given, making the handbook a most attractive guide to a region which hitherto has not been dealt with as a whole.

\section{Catalogue of Fossils}

The Catalogue ${ }^{11}$ of type and figured specimens of fossils in the Geological Survey Gallery of the Royal Scottish Museum will be useful to palæontologists. Localities and references are given. It is noted that the Dunlop collection and the material of the Hugh Miller, Traquair and Neilson Collections in the Natural History Department are outside the scope of the catalogue.

1 "Summary of Progress of the Geological Survey of Great Britain and the Museum of Practical Geology for the Year 1935". Part 1. Pp. viii +98. 1s. 6d. net.

ibid.. Part 2. Pp. $\mathrm{x}+129+7$ plates. 3s. net.
s"The Geology of the Country around Rothbury, Amble and Ashington." By A. Fowler. Pp. xii $+159+5$ plates. $38.6 d$. net. "Gosforth District". By F. M. Trotter, S. E. Hollingworth, T, Eastwood and W. C. C. Rose. Pp. xii $+136+6$ plates. 38 . $6 d$. net. s"The Geology of the Sanquhar Coalfleld and Adjacent Basin of Thornhill"' By J. B. Simpson and J E. Richey, with contributions by A. G. Macgregor. Palæontology by J. Pringle. Pp. viii $+97+6$ plates. $3 s$. net.

British Regional Geology. "The Hampshire Basin and Adjoining "British Regional Geology. "The Hampshire Basin and
Areas". By C. P. Chatwin. Pp. $94+8$ plates. 18. $6 d$. net.

"ibid. "East Anglia and Adjoining Areas". By C. P. Chatwin. Pp. $91+8$ plates. $18.6 d$. net.

s ibid. "The Central England District", By F. H. Edmunds and K. P. Oakley. Pp. $88+8$ plates. 18. $6 d$. net.

- ibid. "The Midland Valley of Scotland". By M. Macgregor and A. G. MacGregor. Pp. $89+8$ plates. 1s. 6 d. net.

${ }^{10}$ ibid. "Scotland: The Northern Highlands" By J. Phemister. Pp. $100+8$ plates. 18.6 d. net.

11 Catalogue of Types and Figured Specimens of Fossils in the Geological Survey Collections now exhibited in the Royal Seottish Museum, Edinburgh". By E. M. Anderson. Pp. 77. 18, 6d. net. (H.M. Stationery Office.)

\title{
Noise on the Road
}

T HE Departmental Committee of the Ministry of Transport, which was appointed in August 1934 to consider the source and prevention of the noises from mechanically propelled vehicles on the road, has issued its fourth and final report*, this time on the subject of warning devices. The Committee, to the work of which we have previously referred, and of which Dr. G. W. C. Kaye has been chairman since shortly after its inception, arranged for experimental measurements to be made of the noise levels of some forty present-day warning devices, in relation to both the annoyance which they excite and their degree of effectiveness under representative road conditions. The measurements were carried out for the Com. mittee by the National Physical Laboratory as heretofore.

The warning devices subjected to test included electric buzzer-operated horns, electric gongs, sirens, Klaxon horns, bulb horns and wind-driven horns. Measured 20 feet away, the figures for the overall loudness ranged from 82 to 113 phons at the front, and from 80 to 104 phons at the side of the warning device.

In the difficult task of assessing the degree of annoyance caused by different types of horns, more than 200 people, both old and young of both sexes, were invited to record their impressions of the various sounds, under the headings of agreeable, tolerable, objectionable, very objectionable, and unbearable. While the divergence in the opinions was perhaps even wider than might have been anticipated, nevertheless the observations, some 30,000 in number, plainly indicated the influence of increasing loudness on the scale of annoyance. There are other factors, of course ; for example, the Committee conclude that horns emitting musical sounds marked by the absence of strong high-frequency components tend in general to be regarded as less annoying than harsh or nonmusical high-pitched sounds of equal loudness. Furthermore, the circumstances, for example, the inconsiderate staccato or sustained operation of a horn by the user, can markedly influence the annoyance factor. But in general, if a single eriterion of

* H.M. Stationery Offce. $18.3 d$. net. annoyance is looked for, which will lend itself to measurement and can be made the basis of regula. tions, then the loudness would seem to fill the bill sufficiently adequately in a large majority of cases.

On this basis, the Committee infers that from the point of view of residents, pedestrians and other quiet road users in relatively quiet streets, horns of loud. ness exceeding 95-100 phons at a distance of 20 feet are likely to cause a material degree of annoyance. In relation to such conditions, it is clear that many present-day motor-horns are excessively loud. From the point of view, however, of a driver subjected to the noise of his own vehicle and who is being followed by another vehicle desirous of overtaking, the tests show that horns of loudnesses of the order of 105 phons may be necessary in the case of vehicles of moderate noise-level, such as private cars and light commercial vehicles, while horns of so much as 110 phons or more may be required to attract the attention of drivers in the cabs of heavy noisy lorries. In such circumstances, horns with very distinctive characteristics are most readily noticeable.

A compromise to meet these diverse requirements had to be arrived at, and the Committee was led to recommend a loudness limit of 100 phons at 20 feet, as one which would result in material improvement as regards annoyance from horns to quiet users of the road, and which would be sufficient to meet the needs of the majority of drivers of vehicles. It points out that, as and when compliance is obtained with the recommendations concerning the level of motorvehicle noise in their previous reports, the difficulty experienced by drivers of very noisy vehicles in hear. ing horns which are not extremely strident will be progressively reduced.

The Committee was given a difficult task, and now that its work has been brought to a successful conclusion, appreciation may be expressed of the way it has directed chief attention to the small and noisy section of road users, so that its recommendations, if brought into force, would not inconvenience the great majority who have consideration for the amenities of the road. 